\title{
Moving an English course online in four days: better safe
}

\section{Tatiana Golechkova}

New Economic School, Moscow, Russia

Keywords: emergency remote teaching; stress reduction; student agency; supportive learning environment; Covid-19.

\section{The challenge}

In spring 2020 educators found themselves in a situation that has been described as emergency remote teaching (Hodges et al., 2020). In Russia the situation with Covid-19 was developing so rapidly during spring 2020 that Higher Education Institutions had to transfer their courses from face-to-face, on-campus delivery to fully online delivery in a matter of days. At our institution, we had four days. This timeframe presented a real challenge: how could we continue supporting our masters' students on an English as a Foreign Language (EFL) course in a new online environment that was only vaguely familiar to us?

Course provision is a complex endeavour requiring thorough planning of learning objectives, pedagogies, classroom procedures, materials, and assessment. Moving these to a different mode of delivery takes time, effort, and relevant training, none of which were available within the four days before our online classes were due to begin. It was quite obvious that it was impossible to move all components of the course online while maintaining the high level of provision the university requires.

\section{The response}

\section{Swift transition: where to begin}


When faced with this challenge, I decided not to do the impossible, but instead to focus on the students and the learning environment. With the levels of stress already soaring due to social and economic instability amid the pandemic, it did not seem reasonable to add to it by introducing spontaneous course adaptations. What seemed important was ensuring that students felt psychologically safe and in control during this abrupt shift, at least within our course. Indeed, we were guided by the sense that high levels of life stress are unlikely to be conducive to learning (Shields et al., 2019; Matos Fialho et al., 2021) and students tend to perform better when they take charge of their own learning (Christenson, Reschly and Wylie, 2012). Following the principles of constructivist pedagogies (Vygotsky and Kozulin, 1989; Powell and Kalina, 2009), I decided to build knowledge of this new mode gradually within our community and attempt to make sense of the online learning and assessment together with the students (Wolverton, 2018), after I had established a supportive and inclusive learning environment.

To establish a comfortable learning environment for my students that would mitigate the effects of uncertainty and stress caused by the pandemic, I planned and introduced two sets of measures within my EFL course. Firstly, I placed an emphasis on communication with the students giving them some agency in taking transition decisions; secondly, I made sure they knew where to look for help in case of a problem, so that they felt supported in our new virtual classroom.

The first group of measures involved communication and agency. In the four days before the shift, we were lucky to have one face-to-face class, in which we discussed the change. I also encouraged students to share their concerns about it and asked them to take an active role in adapting our course to the emergency online delivery. These included negotiating assessment schedule, format of class materials (google docs, Padlet, and word or pdf files), ways to submit homework (email, google drive, university learning management system LMS), time and length of breaks during online classes, additional group communication channels (social networks or messengers), and online platforms for synchronous teaching (university-supported Bluejeans and Zoom).

One of the crucial questions was assessment. Since March was mid semester with most assignments and assessment practices already implemented, I felt the need to assure the Journal of Learning Development in Higher Education, Issue 22: Compendium October 2021 
class that as many of them would remain unchanged as the new mode could allow. The students were involved in deciding whether they wanted to follow the previously approved assessment schedule or to wait until proctoring practices were in place at the institutional level, which would inevitably mean delays. As a result, some groups decided they could trust each other to do in-class assessment without proper proctoring so that the tests were not delayed until the end of the semester, other groups felt more comfortable waiting. Overall, guided by my observations and informal student feedback, we kept changes in the course procedures to the minimum, followed previous scheduling agreements, and involved the class in decisions whenever possible. This provided my students a much-needed sense of stability and control of the situation in those uncertain times.

The other important aspect of facilitating the emergency transition was ensuring that the students felt psychologically safe. It largely involved drawing their attention to solutions to potential problems. It seemed when the students had clear explanations of how the classes were going to run and what issues may arise, they felt less stressed and overwhelmed with the new technologies and class procedure adaptations. One example is challenges with tasks in breakout rooms. To make sure students felt supported, I explained each task, copied prompts into the chat, and regularly reminded students about the Zoom 'ask for help' function. Additionally, we agreed to create Telegram messenger chats for situations that required our prompt attention, e.g., technical issues. The chats complemented standard communication over institutional LMS and email. These chats worked well as an emergency communication channel, as they were available on multiple devices and could operate with unstable connection. They also involved the group with helping each other, unlike more formal email communication with one recipient.

\section{Recommendations}

\section{Support and Agency}

My decision to focus on student agency and supportive learning environment instead of devising a thorough plan of moving each course component to the online mode proved beneficial to the students. My observations and a short student survey showed that despite the stressful overnight change of course delivery mode, students felt psychologically safe in 
the first weeks, which enabled us to gradually negotiate and adapt our classroom procedures and assessment, after which we were able to focus again on learning in a new remote class.

Based on my experience of managing a change in an extremely limited time, I would recommend starting by reducing stress levels, ensuring a supportive environment and encouraging students to play an active role in decision-making, and only then proceeding to pedagogical adaptations. My masters' students found the following helpful: effective communication with the instructor, explicit change management, and involvement in course adaptation decisions. It seems that when students feel psychologically safe and in control, they are more receptive to learning, even if not all course components are adapted to the online mode of delivery. Overall, this emergency transition to remote teaching and learning appeared to be a powerful learning development experience for the whole team, as it provided an opportunity to promote students' self-sufficiency, autonomy, flexibility, and responsibility for, and active participation in, learning.

\section{References}

Christenson, S. L., Reschly, A. L., and Wylie, C. (eds.) (2012) The handbook of research on student engagement. New York: Springer Science. https://doi.org/10.1007/978-1-46142018-7.

Hodges, C., Moore, S., Lockee, B., Trust, T. and Bond, A. (2020) 'The difference between emergency remote teaching and online learning', Educause review, 27, pp.1-12. Available at: https://er.educause.edu/articles/2020/3/the-difference-betweenemergency-remote-teaching-and-online-learning (Accessed: 5 June 2021).

Matos Fialho, P. M., Spatafora, F., Kühne, L., Busse, H., Helmer, S. M., Zeeb, H., Stock, C., Wendt, C. and Pischke, C. R. (2021) 'Perceptions of study conditions and depressive symptoms during the COVID-19 pandemic among university students in Germany: results of the International COVID-19 student well-being study', Frontiers in public health, 9, p.674665. https://doi.org/10.3389/fpubh.2021.674665. 
Powell, K. C. and Kalina, C. J. (2009) 'Cognitive and social constructivism: developing tools for an effective classroom', Education, 130, pp. 241-250.

Shields, S. G., Ramey, M. M., Slavich, G. M. and Yonelinas, A. P. (2019) 'Determining the mechanisms through which recent life stress predicts working memory impairments: precision or capacity?', Stress, 22(2), pp.280-285. https://doi.org/10.1080/10253890.2018.1556635.

Vygotsky, L. S. and Kozulin, A. (1989) Thought and language. Cambridge, MA: MIT Press.

Wolverton, C.C., (2018) 'Utilizing synchronous discussions to create an engaged classroom in online executive education', International Journal of Management in Education, 16 (2), pp.239-244. https://doi.org/10.1016/.ijme.2018.03.001.

\section{Author details}

Tatiana Golechkova is Assistant Professor in the Department of Humanities and Foreign Languages, the New Economic School, Moscow, Russia. She holds a PhD in Cognitive Linguistics and a Cambridge Delta. She has broad experience of teaching English for Academic and Specific Academic Purposes to undergraduate and graduate students, as well as academics. Her areas of special interest include strategies for effective academic communication, developing learning autonomy, and genre features of English academic texts. 